\title{
Dünya ve Türkiye Üniversitelerinde Girişimcilik Bölümlerinin Artan Önemi: Lisans ve Lisansüstü Eğitim Düzeyinde Bir Araştırma $^{1}$
}

\author{
Yasin KARADENIZ² ve Çiğdem ÖZKAN ${ }^{3}$
}

Öz

Girişimciliğin gelişmesinde üniversitelerin girişimci bir yapıya ulaşmayı hedeflemeleri kadar üniversitelerde girişimcilik bölümlerinin ve eğitimlerinin yaygınlaştırılması, böylece kişilerin girişimcilik özelliklerinin geliştirilmesi de önemlidir. Araştırmada, girişimcilik eğitiminde Türkiye'nin mevcut durumu, Türkiye'deki üniversiteler ile The Times Higher Education tarafindan hazırlanan "Dünyanın En İyi Üniversiteleri Listesi”ndeki ilk on üniversitedeki doğrudan girişimcilik lisans ve lisansüstü bölümleri tespit edilerek ve karşılaştırmalar yapılarak değerlendirilmiştir. Türkiye'deki üniversitelerin durumuna YÖK Lisans atlas verilerine ve üniversitelerin sosyal bilimler enstitülerinin resmi internet adreslerine bakılarak, Dünyadaki ilk on üniversitenin lisans, yüksek lisans ve doktora programlarına ise ilgili üniversitelerin internet adreslerinden ulaşılarak "içerik analizi” yapılmıştır. Bu bağlamda, üniversitelerde girişimcilik eğitiminin, "yalnızca bazı programların ders planlarında yer alan bir ders" olarak sınırlı kalmaması; doğrudan girişimcilik alanında eğitim veren programların sayısının, niteliğinin artması ve farklı disiplinlere de yayılmasının gerekli olduğu düşünülmektedir.

Anahtar Kelimeler: Girişimcilik, Girişimcilik Eğitimi, Girişimcilik Lisans Programları, Girişimcilik Lisansüstü Programlar1

Increasing Importance of the Entrepreneurship Departments in Universities of the World and Turkey: A Survey at the Level of Undergraduate and Graduate Programs

\begin{abstract}
In the development of entrepreneurship, it is important for universities both to reach to an entrepreneurial structure and to mainstream entrepreneurship departments and education through which people improve their entrepreneurial qualities. In the study, the current situation in Turkey in entrepreneurship education is evaluated by identifying and comparing the direct entrepreneurship undergraduate and graduate programs of the universities in Turkey and of the top ten universities included in the List of World's Best Universities that has been prepared by The Times Higher Education. In this survey, a "content analysis" is performed through investigating the conditions of the universities in Turkey by analyzing the atlas data of The Council of Higher Education (YÖK) and the official websites of the institute of social sciences of the universities, and by accessing the undergraduate, graduate and PHD programs of the World's Top Ten Universities through their websites. In this context, the entrepreneurship education at universities should not be considered as "a course included only in the curriculum of some programs"; instead, the number and qualities of the programs that provide education in the field of entrepreneurship should be increased and spread to different disciplines.
\end{abstract}

Key Words: Entrepreneurship, Entrepreneurship Education, Entrepreneurship Undergraduate Programs, Entrepreneurship Graduate Programs

\section{Atıf İçin / Please Cite As:}

Karadeniz, Y. ve Özkan, Ç. (2020). Dünya ve Türkiye üniversitelerinde girişimcilik bölümlerinin artan önemi: Lisans ve lisansüstü eğitim düzeyinde bir araştırma. Manas Sosyal Araștırmalar Dergisi, 9(2), 872-885.

Geliş Tarihi / Received Date: 06.02.2019

Kabul Tarihi / Accepted Date: 28.10.2019

\footnotetext{
${ }^{1}$ Çanakkale'de düzenlenen 7. Uluslararası İşletme Yönetimi Kongresi'nde sunulan bildiriden üretilmiştir.

2 Dr. Öğr. Üyesi Yasin KARADENIZ - Çanakkale Onsekiz Mart Üniversitesi, Ayvacık Meslek Yüksekokulu ykaradeniz@comu.edu.tr, ORCID: 0000-0002-5609-5171

3 Dr. Öğr. Üyesi Çiğdem ÖZKAN - Çanakkale Onsekiz Mart Üniversitesi, Ayvacık Meslek Yüksekokulu cigdemozkan@comu.edu.tr,ORCID:0000-0002-9823-4117
} 


\section{Giriş}

Ülke ekonomilerinde yaşanan sorunların düzelmesi ve ekonominin gelişmesinde, toplumsal kalkınmanın sağlanabilmesinde, girişimcilik büyük öneme sahiptir. Son zamanlarda özellikle gelişmekte olan ülkelerde girişimcilik ile ilgili konuların üzerinde önemle durulmaktadır. Bu kapsamda üniversitelerde ögrencilerin girişimcilik ruhlarını geliştirmek ve mezun olduklarında kendi işletmelerini açarak; ekonomi, istihdam gibi konulara katkı sağlamaları amaçlarıyla birçok bölüm ve programda girişimcilik dersleri yaygınlaşmakta ve girişimcilik merkezleri kurularak, bu merkezlerde de öğrencilere girişimcilikle ilgili uygulamalı proje eğitimleri verilmektedir. Girişimcilik eğitiminde yaşanan bu olumlu gelişmelere, son zamanlarda Dünya ve Türkiye üniversitelerinde doğrudan açılan, Girişimcilik Anabilim Dallarının ve girişimcilik lisans ve lisansüstü programlarının da önemli katkılar sağlayacağı düşünülmektedir.

Bu çalışmanın amacı, Dünya ve Türkiye üniversitelerde açılmış olan doğrudan girişimcilikle ilgili lisans ve lisansüstü programlarının durumunu karşılaştırmalı bir şekilde ortaya koymak ve bu programların başarılı girişimcilerin yetişmesi ve ülke ekonomileri açısından katkısını açıklamaktır. Çalışmada ilk önce girişimcilik kavramı ve girişimciliğin önemi üzerinde durulmuştur. Daha sonra girişimcilik eğitimi ve bu alanda yapılan bazı çalısmaları kapsayan literatür incelemesi verilmiştir. Son olarak ise, Türkiye'deki üniversitelerin doğrudan girişimcilik lisans bölümlerine YÖK Lisans atlas verilerine, girişimcilik lisansüstü bölümlerine, üniversitelerin sosyal bilimler enstitülerinin resmi internet adreslerine bakılarak, Dünyadaki doğrudan girişimcilik bölümleri açan önemli üniversitelerin lisans, yüksek lisans ve doktora programlarının durumuna ise ilgili üniversitelerin internet adreslerinden ulaşılarak "içerik analizi" yapılmış ve elde edilen bulgular açıklanmıstır.

\section{Girişimcilik, Girişimci Kavramı ve Önemi}

Girişimcilik kavramının literatürdeki tanımlarına bakıldığında pek çok yazarın farklı bakış açılarıyla tanımlamaya çalıştkları görülmektedir. Kavramla ilgili yapılan bütün tanımlamalarda ortak nokta, girişimciliğin çeşitli firsatların değerlendirildiği bir süreç olarak görülmesidir (İşcan ve Kaygın, 2011, s. 276). Girişimcilik kavramı Fransızca "entreprende" ve Almanca "unternehmen" kelimelerinden türemiş ve Türkçede ise "üstlenmek" anlamına gelen bir kavram olarak kullanılmaktadır (Akdemir, 2009, s. 25).

Girişimci ise kısaca işletmeyi kuran, yönlendiren, geleceğe ilişkin planları yapan ve yürüten kişi olarak ifade edilebilir. Girişimciliğe ilişkin yaygınlıkla yapılan bir tanım da şöyledir: "Belirli işletmecilik faaliyetlerini realize etmek amacıyla sahip olduğu finansal kaynakları riske eden ve kar amacı güden kişiler" (Akdemir, 2009, s. 25). Diğer bir tanıma göre ise, girişimci, mal ve hizmet üretimini gerçekleştirebilmek amacıyla riski üstlenerek doğal kaynak, sermaye, emek gibi üretim öğelerini bir araya getirip faaliyete geçiren kişidir olarak tanımlanabilir (Tekin, 2004, s. 3).

Girişimci yeni düșüncelerin yaratılması, yayılması ve uygulamasını hızlandırır, ayrıca yeni endüstrilerin doğmasına yol açar, teknolojileri kullanan sektörlerde verimliliği artırır ve hızla büyüyen sektörler yarattı̆ğ için ekonomik büyümeyi hızlandırır. Dolayısıyla girişimci, ekonomik faaliyetlerin düzenlenmesinde, istihdam yaratılmasında ve üretim faaliyetlerinde anahtar faktördür (Bozkurt Çetinkaya, 2011, s. 10-11).

Girişimcilik bir ülke ekonomisi için önemli olup, girişimciler, iş hayatının sürükleyici bir unsuru olarak kabul edilmektedir. Bir ülke ekonomik sistemi içerisinde girişimciler, buluş yaparlar, yeni işler kurarlar ve ekonomik büyümeye yardımcı olurlar. Girişimciler, bir ülkede büyüyen ve üretken bir ekonominin gereği olarak risk üstlenebilen işletmeciliğin itici güçleridir. Günümüzde her y1l birçok kişi girişimci olarak yeni işler kurmakta ve iktisadi gelişmenin ve kalkınmanın dinamiği olmaktadırlar (Yılmaz vd., 2010, s. 158).

Girişimcilik, pazardaki firsatların iş fikrine dönüştürülerek yeni iş ve işletmelerin oluşturulduğu dinamik bir süreçtir. Bu sürecin en önemli unsuru olan girişimcinin, çeşitli nedenlerle girişimcilik yaptı̆ğ görülmektedir. Girişimci olmanın dört temel güdüsü bulunmaktadır (Segal vd., 2005, s. 42-57):

- Kar elde etmek,

- Kendinin patronu olmak,

- Kişisel tatmin elde etmek,

- Tercih edilen yaşam biçimini kurmak.

2017 yllında yayınlanan, 2017 BNP Paribas Küresel Girişimcilik Raporu'nda, girişimcilere en çok kazandıran sektör ise, bilgi teknolojileri olarak gösterilirken, onu online, mobil ve dijital takip ediyor. 
Listenin üçüncü sırasını ise üretim ve perakende alıyor. Girişimciler için en büyük firsatları sunan ülkeler ise ABD, Çin ve Almanya şeklinde sıralanıyor. Rapor bu yıl ilk kez elit girişimcileri de kendi aralarında sınıflandırmıştır. BNP Paribas'a göre elit girişimciliğin dört türü ise şöyle ifade edilmiştir (https://www.melekyatirimplatformu.com/tr, Erişim Tarihi 26.03.2018):

- Ultra Girişimci: Yatırılabilir net serveti 25 milyon doların üzerinde olan girişimci.

- Genç Girişimci: 1980 ile 2000 yılları arasında doğmuş girişimci.

- Deneyimli Girişsimci: 55 ve üzeri yaşındaki, ikinci dünya savaşı ile soğuk savaş arasındaki dönemde doğmuş girişimci.

- Seri Girişimci: Dört veya daha fazla faal girişim kurmuş girişimci.

Girişimlerin kurulması ve yaşama süreleri ülkeler için tesadüflere bırakılamayacak kadar önem arz etmektedir. Yaşanan ekonomik krizlerle beraber tüm dünyada ve ülkemizde işsiz sayısının artması, bilinçli ve sistemli bir şekilde girişimci yetiştirme ihtiyacını ve bundan sorumlu olacak kurumları gündeme getirmektedir. Özellikle gelişmekte olan ülke ekonomileri için girişimcilik ekonomik gelişimin motoru olarak görülmekte ve ekonomide kritik bir role sahip olmaktadır. Bu nedenle KOBİ'lerin kurulması ve büyümesi ulusal ekonomi politikaları ile de desteklenmektedir.

Ekonomik hareketliliğin toplum içerisinde arttırılması ve yaygınlaştırılmasında girişimciliğe önemli roller düşmektedir. Ekonomik kalkınma sürecinin sağlanabilmesi ve toplumsal refah düzeyinin arttırlması için, toplumsal ihtiyaçlara cevap verebilecek gelişmeye açık, başarılı girişimcilerin faaliyete geçirilmesine gerek duyulmaktadır. Girişimciler, ülkenin sosyal, kültürel ve siyasi gelişmesini de etkilemekte ve bu gelişmelerde de belirleyici rol oynamaktadır. Bu nedenle günümüzde girişimciliğe verilen önem daha da artmıştır (Akpınar, 2009, s. 15).

\section{Girişimcilik Eğitimi, Amacı ve Üniversiteler}

Eğitim girişimciliğin ortaya çıkmasındaki ve gelişmesindeki en büyük yardımcı faktörlerden biridir. Eğitim sadece girişimciliğin başlangıç aşaması için değil girişimciliğin ilerleyen aşamalarında karşılaşılan problemlerin çözümünde de yardımcı olmaktadır. Her ne kadar girişimcilik eğitiminin açık bir tanımı olmasa da, amaç işletmelerin etkin bir şekilde oluşturulmasını teşvik etmektir. Girişimcilik eğitiminin genel işletme ve ekonomi eğitimi ile karıştırılmaması gerekir. Bu eğitimlerin amacı yaratıcllğı, serbest meslek ve yeniliği yükseltmektir. (Bozkurt Çetinkaya, 2011, s. 29).

Girişimcilik eğitimi, Japonya'daki Kobe Üniversitesinde 1938 yllında Shigeru Fijii tarafından başlatılmıstır. Dünyada küçük işletme yönetimi kursları 1940'larda ortaya çıkmaya başlamıştır (Sexton ve Bowman, 1987, s. 35).

Dünyada 1971 yllında girişimcilik üzerine master, 1972'de ilk kez lisans eğitiminin ardından girișimcilik eğitimi kök salmaya başlamıştır. 1980’lerin başında 300'ün üzerindeki üniversitede girişimcilik ve küçük işletme yönetimi dersi verilirken, 1990’larda bu say1 1050'lere kadar büyümüştür (Solomon vd., 1994, s. 65).

1950’lerde ortaya çıkan işletme disiplinin girişimciyi ve girişimciliği ciddi düzeyde incelemesi son 20 ylllık bir gelişmenin ürünüdür. ABD'de girişimcilik 1980'lerden itibaren derslere yoğun olarak dahil edilmiştir. Girişimcilik günümüzde birçok okulda başı başına bir ders olmanın ötesinde yüksek lisans ve doktora derecesi verilen bir alandır. 1990’larda birçok işletme okulunda girişimcilik merkezleri açılmıştır (Çetindamar, 2002; Bozkurt Çetinkaya, 2011, s. 30).

Girişimcilik eğitiminin birey ve işletme bazındaki olumlu etkilerinin yanı sıra ülke bazındaki etkileri de oldukça önemlidir. İstihdam ve yenilikçilik başta olmak üzere ülkelerin ekonomik kalkınmalarında önemli bir rol oynamaktadır (Balaban ve Özdemir, 2008, s. 137).

Girişimcilik eğitiminin genel kabul görmüş bir tanımının olmaması girişimcilik eğitiminin amaçlarına da yansımış durumdadır. Dünyada girişimcilik eğitimi üzerine araştırma yapanların çoğunun farklı amaçlar sundukları görülmektedir (Bozkurt Çetinkaya, 2011, s. 31).

Rasmussen ve Sorheim’a gore (2006, s. 185) girişimcilik eğitiminde amaç, girişimci kişiliği ortaya ç1karmaktır.

Raposo ve Paço’ya (2011, s. 453) göre girişimcilik eğitiminin amaçları şunlardır:

- Girişimcilikle ilgili faydalı bilgi almak, 
- Tekniklerin kullanımıyla kapasite artısıı, işletme durumunun incelenmesi ve eylem planlarının oluşturulması,

- Girişimcilik yeteneklerini belirlemek ve teşvik etmek

- Girişimciliğin bütün konularında desteklemek ve empati geliştirmek,

- Değişime yönelik tutumları geliştirmek,

- Yeni başlayanları ve diğer girişimcileri teşvik etmek.

Türkiye'de de dünyaya paralel olarak son yıllarda girişimcilik ve girişimcilik eğitimi konularında, farklı amaçlarla yapılmış çok sayıda araştırma olduğu literatür incelemelerinde görülmektedir. Girişimciliğin gelişiminde en önemli faktörlerden biri, bu konuda verilen eğitimlerin yaygınlaştırılması ve kişilerin girişimcilik özelliklerinin geliştirilmesidir. Girişimcilik eğitimi ile girişimcilik faaliyetleri arasında olumlu bir ilişki olduğuna dair birçok araştırma bulunmaktadır ve bu da girişimcilik eğitiminin incelenme gerekliliğini ortaya çıkarmaktadır.

Girişimcilik eğitimi konusunda yapılan ilk araştırmalarda girişimcilik, küçük işletme kavramı etkisiyle "bir iş yeri satın alma", "yenilik ihtiyacı ve büyüme ihtiyacı" gibi imajlarla değerlendirilmiştir. Daha sonra girişimcilik kavramının "küçük işletme" kavramından uzaklaşarak gerçek anlamında kullanılmaya başlanmasıyla girişimciliğe bakışta ortaya çıkan farklıık, girişimciliğin bağımsız bir disiplin olarak fark edilmesini sağlamıştır (Tağraf ve Halis, 2008, s. 91). Girişimciliğin bir disiplin olarak değerlendirilmesiyle girişimciliğin öğrenilemeyeceği görüşünü diğer bir ifadeyle girişimciliğin doğuştan geldiğine ilişkin ortaya çıkan görüşün değişerek girişimcilik eğitimin yapılabileceği ve böylece girişimciliğin değişik yönleri ile öğretilebileceği görüşü kabul görmeye başlamıştır. Drucker, girişimciliği tanımlarken "girişimcilik mistik bir durum mudur? Girişimcilik bir sihir değildir, gizem değildir. Girişimcilik bir disiplindir ve herhangi bir disiplinde olduğu gibi öğrenilebilir" ifadesini kullanmaktadır. Girişimcilik konusunda ulaşılan bu yarg1, bakış açısını değiştirmiş ve girişimcilik eğitimi yapılabileceği görüssleri belirmiştir (Kuratko, 2005 Akt: Tağraf ve Halis, 2008, s. 92).

Girişime başlamadan önce girişimcilik eğitiminin verilmesi bireylerin gelecekte yapacakları girişimlerin başarı şansını arttırması açısından önemlidir. Özellikle gençlerin girişimsel ve tutumsal davranışlarının oluşmasında girişimcilik eğitiminin büyük önem taşıdığı, söz konusu eğitimin öğrencilerdeki girişimcilik potansiyelini ortaya çıkarmaya yardımcı olduğu ve kendi işlerini kurmaya yönlendirdiği ifade edilmektedir. Örneğin, ABD'de yapılan bir araştırmada girişimcilik eğitimi alan kişilerin (Soylu ve Kepenek, 2008, s. 459 - 461);

- Yeni iş kurmada üç kat daha fazla eğilime sahip olduğu,

- Kendi işinde çalışmaya üç kat daha fazla istekli olduğu,

- Ylllı \% 27 daha fazla gelir elde ettiği,

- Mal varlıklarının \% 62 daha fazla olduğu,

- Çalıştıkları işte daha fazla tatmin sağladıkları belirlenmiştir.

Girişimcilik kültürünün oluşturulması, girişimciliğin öğretilmesi, etkin bir şekilde yayılmasında eğitim kurumları çok önemli bir işlev görmektedir. Eğitim kurumlarınca öğrencilerde girişimcilik bilincinin oluşturulmasına ve öğrencilerin girişimcilik yönlerinin geliştirilmesine yönelik çeşitli eğitimlerin verilmesi, iş dünyasından profesyonellerin pratik deneyimlerinden öğrencilerin yararlandırılmasına yönelik gerçekleştirilen uygulamalar ve bu uygulamalardan elde edilen veriler girişimcilik ve eğitim arasındaki ilişkinin çok güçlü olduğunu ortaya koymuştur.

Örneğin Berglund ve Wennberg (2006) yüksek lisans düzeyinde girişimcilik eğitimi alan işletme ve mühendislik bölümü öğrencilerinin girişimcilik eğilimlerini kişilik testi ve görüşme yaparak araştırmışlardır. Araştırmaya göre; her iki bölüm öğrencilerinin de girişimcilik eğilimlerinin yüksek olduğu, mühendislik öğrencilerinin pratik ve çaba gerektiren girişimlere yöneldiği, işletme öğrencilerinin ise daha kuramsal ve daha açı pazarlara odaklandığı bulunmuştur.

Üniversitedeki girişimcilik eğitiminin mezun olduktan sonraki etkilerini gösteren deneysel bir çalışma Galloway ve Brown (2002) tarafindan gerçekleştirilmiştir. Çalışmada üniversite eğitimleri esnasında girişimcilik merkezinden bir programa kayıt olmuş ve hiçbir girişimcilik çalışmasına katılmamış olmak üzere hem mezun hem de halen ögretim hayatına devam eden öğrenci grupları üzerinde telefon anketi 
uygulanmıştır. Sonuçta girişimcilik hırsı ve istekliliğinin artması için girişimcilik eğitimlerinin etkili olduğunu tespit etmişlerdir.

Şengel (2008) ise; bir ülkenin kalkınmasında, rekabet gücünün arttırılmasında, istihdamın sağlanmasında, ekonomik gücün arttrrılmasında girişimciliğin teşviki ve girişimcilik eğitimi konularına değinerek, Anadolu Üniversitesi ve Bilecik Üniversiteleri'ndeki akademik birimlerde ön lisans ve lisans düzeyinde verilen girişimcilik dersinin, öğrencilerin inovatif iş fikrine ulaşmada olumlu etkileri olduğu sonucuna ulaşmıstır.

Küçük (2009) ise çalışmasında, Türkiye'de girişimcilik eğitimi üzerinde durarak, Türk Milli Eğitim Sistemi’nde girişimcilik eğitimine değinmiş, $\mathrm{AB}$ hibe projesi kapsamında gerçekleştirilen bir girişimcilik eğitimini örnek olarak sunmuştur.

Güler (2009), ABD'den en iyi 20 ve ABD dışı dünyadan en iyi 10 üniversitenin web sitelerine erişerek bu üniversitelerin "Sosyal Girişimcilik" ile ilgili eğitsel ve akademik çalışmaları hakkında bilgi toplamıştır. Çalışmanın içerik analizinde kriterler olarak üniversitelerdeki dersler, araştırma/bilim merkezleri, bilimsel dergiler, yayınlanmış makaleler, yayınlanmış kitaplar, konuyla ilgili çalışan öğretim üyeleri, burslar, konferanslar, kulüpler ve yarışmalar, staj ve topluma hitap eden özelliği bulunan projeler incelenmiştir. Çalışma sonucunda sosyal girişimcilik içerikli derslerin işletme fakültelerinde daha yoğun okutulduğu, ABD üniversitelerinin diğer ülkelere göre daha aktif olduğu ve konu hakkındaki eğitsel faaliyetlerin bilimsel faaliyetlere göre daha fazla yapıldığı gibi sonuçlara ulaşmışlardır.

Yelkikalan vd. (2010), yaptıkları çalş̧mada, girişimcilik eğitiminin hem Türkiye hem de dünya üniversitelerinde önemli bir yere sahip olduğunu ortaya koymuştur. Türkiye üniversitelerine bakıldı̆̆inda ön lisansta girişimcilik derslerinin, lisans ve lisansüstü eğitim programlarına göre daha ağırlıklı olduğu anlaşılmıştır. Kimyacılar, biyologlar, mühendisler ya da ziraatçılar için ayrı ayırı girişimcilik programlarının olması dikkat çekicidir. Ayrıca bazı dünya üniversitelerinde mühendislik, biyoloji, uzay teknolojileri gibi alanlarda da faaliyet gösteren birimlerde inovasyon ve girişimcilik gibi derslerin varllğı, girişimcilik konusunun ilerleyen zamanlarda daha sık telaffuz edilip, geleceği gören birçok üniversitenin vizyonuna gireceğinin bir göstergesidir.

Bozkurt Çetinkaya (2011)'de “Dünyada ve Türkiye'de Girişimcilik Eğitimi” kitabında üniversitelerde girişimcilik dersini veren öğretim elamanları ile piyasada başarılı olmuş girişimcilerin görüşlerini alarak "Girişimcilik" dersinin piyasa koşullarına ne derecede uygun olduğunu belirlemeye çalışmışır.

Girişimcilik eğitimlerinin başarılı sonuçlar vermesinde, kuşkusuz üniversitelerin rolü büyüktür. Üniversitelerdeki girişimcilik eğitimi öğrencilerin değişen derecelerde iş kurmasını sağlamaktır. Bu büyük ölçüde girişimcilik eğitiminin türüne göre belirlenir. Üniversitelerdeki girişimcilik eğitimleri, öğrencilerin sadece girişimcilik niyetlerini dinamik hale getirmekle kalmamakta, aynı zamanda iyi bir girişimci olmaları için gerekli olan davranış normları hakkında da bilgi sahibi olmalarına yardım etmektedir (Liñán vd., 2008, s. 45).

Üniversitelerde bilgi üretiminin piyasa normlarına göre ve piyasa için yapılanması "girişimci üniversite" kavramını ortaya çıkarmıştır. Bu paradigmayla üniversitelerin, kendi kaynaklarını kendileri yaratan, piyasayla işbirliği yapan ve sürekli rekabet içinde olan "girişimci" kimlikte olması amaçlanmaktadır. "Girişimci üniversite" anlayışında bilginin piyasa sürecinde rekabette öne geçmeyi sağlayacak ve karlllı̆̆1 artıracak bilgi üretimine öncelik verildiği görülmektedir (Özdem ve Sarı, 2008, s. 3-4).

Geçtiğimiz günlerde, Türkiye Bilimsel ve Teknolojik Araştırma Kurumu (TÜBİTAK) tarafindan, “Girişimci ve Yenilikçi Üniversite Endeksi 2017” sonuçları açıklanmıştır. Endeks hazırlanırken bilimsel ve teknolojik araştırma yetkinliği, fikri mülkiyet havuzu, iş birliği ve etkileşim, girişimcilik ve yenilikçilik kültürü ile ekonomik katk1 ve ticarileşme boyutları altında 23 gösterge dikkate alınmıştır. Buna göre, 2017 yllında Türkiye'nin en girişimci ve yenilikçi üniversiteleri ilk 10 sıralaması aşağıdaki gibidir:

1. Sabancı Üniversitesi

2. Orta Doğu Teknik Üniversitesi

3. Gebze Teknik Üniversitesi

4. İstanbul Teknik Üniversitesi

5. Boğaziçi Üniversitesi

6. İhsan Doğramacı Bilkent Üniversitesi

7. Koç Üniversitesi

8. İzmir Yüksek Teknoloji Enstitüsü 


\section{9. Özyeğin Üniversitesi}

10. Yıldız Teknik Üniversitesi

Girişimci ve Yenilikçi Üniversite Endeksi sonuçlarının, üniversiteler tarafindan detaylı biçimde incelenmesi ve üniversitelerin verdikleri eğitimle hem öğrencilerini hem de kendilerini çağa uygun biçimde dönüştürmeleri, tüm dünyada girişimcilikten beklenen faydaların elde edilebilmesi açısından çok önemlidir.

Türkiye'deki üniversiteler önlisans düzeyinde incelendiğinde, doğrudan girişimcilik programlarının sayısının son derece yetersiz olduğu görülmektedir. 2018 yılı itibarıla üniversitelerin iki yıllık ön lisans düzeyinde doğrudan girişimcilik programı bulunmamaktadır. Ön lisans seviyesinde girişimcilik eğitimi ise, özellikle işletme yönetimi vb. programlarda sadece girişimcilik dersi adı altında verilmektedir. Son yıllarda meslek yüksekokullarının bazı programlarında girişimcilik dersini alan ve başarı ile tamamlayan öğrencilere, KOSGEB onaylı girişimcilik eğitim sertifikaları verilmesi ise öğrencilerin girişimcilik bilinçlerinin artması ve girişimcilik motivasyonlarının oluşması açısından olumlu bir gelişmedir.

Üniversiteler lisans ve lisansüstü düzeyde incelendiğinde ise, açlan doğrudan girişimcilik programlarının sayısı yeterli olmamakla birlikte, dünyaya paralel olarak ülkemizde de gelişim göstermektedir. Bu konu ile ilgili ayrıntılara, çalışmanın bir sonraki bölümünde detaylı yer verilmiştir.

\section{Dünya ve Türkiye Üniversitelerinde Girişimcilik Bölümlerinin Lisans ve Lisansüstü Eğitimi Düzeyinde Karşılaştırmalı Analizi}

Girişimcilik eğitimi; girişimin desteklenmesi, teşvik edilmesi ve gelişiminde önemli bir rol oynamaktadır. Bundan dolayı da, tüm dünyada üniversitelerde bu eğitimin verilmesi ile ilgili gelişmeler yaşanmaktadır. Eğitim sisteminin birçok düzeyinde yer almaya başlayan girişimcilik eğitim programlarının yanı sıra günümüzde girişimcilik alanında verilen kurslar, üniversitelerde açılan girişimcilik merkezleri ve artan akademisyen sayıları, doğrudan girişimcilik lisans ve lisansüstü programların sayılarında da görülen artış bu durumun bir göstergesi olmaktadır.

Dünyada girişimcilik eğitimine bakıldığında, ABD’nin ilk sırada yer aldığı görülmektedir. Girişimcilik ile ilgili Amerika'da ilk eğitim 1947 yllında Harvard Business School'da verilmeye başlanmıştır. Bu konudaki ilk akademik programlar ise 1960'lı yıllarda başlamış ve giderek yaygınlaşmıştır. Koh'un (1996) araştırmasına göre, 1993 yllında 400'den fazla ABD üniversitesinde lisans veya yüksek lisans düzeyinde girişimcilik dersleri verilirken, bu say1 2003 yllinda 1600’lere ulaşmıştır (Akt: Gürol ve Bal, 2009, s. 14).

Dünya ve Türkiye üniversitelerinde girişimcilik merkezleri aracıllğı ile tüm üniversiteye girişimcilik kültürünün aşılanmaya çalışılması ve bu merkezlerin üniversitelerde çeşitli girişimcilik faaliyetleri göstermesi, sadece ders bazında girişimciliğin yeterli olmadığını göstermektedir. Özellikle dünya üniversitelerinde alanlarında başarılı girişimcilerin bulunduğu konferans ve seminer programları, tüm üniversite bölümlerine hitap eden bir yapiya kavuşturulmuştur.

Ayrıca Türkiye üniversitelerinde de son zamanlarda girişimciliğin bir ders olarak verilmesinin dışında, dünya üniversitelerine paralel olarak doğrudan girişimcilik lisans ve lisansüstü bölümlerin açılmaya başlaması ve bu bölümlerin sayısındaki artış, girişimcilik ruhunun gelişmesi ve buna bağlı olarak ülke ekonomilerinin kalkınmasında önemli rol oynayacaktır.

Girişimcilik eğitiminin oldukça önemli olması ve öneminin de gittikçe artmasına karşın, bu alana ilişkin eğitim veren üniversitelerdeki girişimcilik bölümlerinin sayıları çok azdır.

Üniversitelerdeki girişimcilik bölümleri, gençlere önlerine çıkacak fırsatları fark etmelerine, sağlıklı ve doğru kararlar alarak bunları iş fikrine dönüştürmelerine, bu fikirlerin üretime dönüştürülerek kar elde edilebilir ürün ve hizmetler ortaya çıkarmalarına yardımcı olmak ve istihdam yaratan, yeniliğe açık, modern, vizyon sahibi işletmeler kurmaları konusunda eğitim vermeyi hedeflemektedir.

Ülkelerin kendi girişimcilerini yetiştirmesinin ve desteklemesinin gerekliliği ekonomik koşullarnn ve istihdam olanaklarının değişmesiyle daha da iyi anlaşılmaktadır. Bu nedenle, globalleşen ekonomik koşullara karșı tüm ülkeler kendi girişimcilerini destekleyerek ülke içinde girișimcilik eğitimini daha iyi planlamak ve içeriğini geliştirmek durumundadırlar. Özellikle, girişimcilik dersinin tüm eğitim programlarnna yetiştirilmesi, okul öncesi dönemden yükseköğrenime kadar bireylerin girişimcilik bağlamında uyarılması, girişimcilik algılarının geliştirilmesi ve yaratıcılık temelli girişimciliğe motive edilmesinin sağlanması önemli bir husustur. 
Üniversitelerde ise girişimcilik dersinin sadece işletme okullarının programlarında değil, diğer bilim dallarında da zorunlu olması, özellikle mühendislik bilimi ile ilgili bölümlerde ders programlarında girişimcilik dersi verilmesi yararlı olacaktır. Ayrıca Türkiye'de lisans ve lisansüstü eğitim düzeyinde üniversitelerde yeni girişimcilik programların açılmasıyla girişimcilik eğitiminin yaygınlaşması ve girişimcilikle ilgili nitelikli bilimsel araştırmaların sayısının artması, dünyaya göre eksikliklerin giderilerek girişimciliğin daha özgün ve işlevsel bir yapıya kavuşturulması daha başarılı girişimcilerin yetiştirilmesi için önemli bir adım olacaktır.

Çalışmada, Dünya ve Türkiye üniversitelerinde sayıları gün geçtikçe artan girişimcilik lisans ve lisansüstü bölümlerinin genel durumu içerik analizi yöntemi ile incelenerek, Dünya'da ve Türkiye'de girişimciliğin gelişmesinde, bu bölümlerin önemi, girişimcilik eğitimi bağlamında açıklanmaya çalışılmışır.

\section{Yöntem}

Araştırmada, Türkiye'deki üniversiteler ile The Times Higher Education tarafindan hazırlanan Dünyanın en iyi üniversiteleri listesindeki ilk on üniversitenin girişimcilik lisans ve lisansüstü programları incelenmiştir. Böylece, girişimcilik eğitiminde Türkiye'nin mevcut durumu, en iyi Dünya üniversiteleri ile karşılaşıtırlarak; girişimcilik eğitiminin, Türkiye'de girişimciliğin gelişmesindeki katkısı ve önemi açılanmak istenmiştir.

Türkiye üniversitelerin girişimcilik lisans ve lisansüstü bölümlerine YÖK lisans atlas verilerinden ve üniversitelerin sosyal bilimler enstitülerinin resmi internet adreslerinden, Dünya'daki en iyi ilk on üniversitenin lisans, yüksek lisans ve doktora bölümlerine ise ilgili üniversitelerin internet adreslerinden, ulaşılarak içerik analizi yapılmıştır. İçerik analizinin amacı, toplanan verileri açıklayabilecek kavramlara ulaşmaktır. İçerik analizinde, birbirine benzeyen veriler belirli kavramlar ve temalar çerçevesinde bir araya getirilerek, okuyucunun anlayacağı bir biçimde düzenlenerek yorumlanmaktadır (Yıldırım ve Şimşek, 2008, s. 227).

\section{Evren - Örneklem}

Araştırmanın evrenini Türkiye'deki girişimcilik lisans ve lisansüstü bölümleri ile The Times Higher Education tarafindan yayınlanan "2018 yılı dünyanın en iyi üniversiteler’" sıralamasındaki ilk on dünya üniversiteleri oluşturmaktadır. Bu araştırmada, Türkiye üniversitelerindeki girişimcilik lisans ve lisansüstü bölümlerinin durum tespiti, YÖK lisans atlas verilerine ve üniversitelerin sosyal bilimler enstitülerinin resmi internet adreslerine bakilarak, Dünya'daki ilk on üniversitenin lisans, yüksek lisans ve doktora programlarına ise ilgili üniversitelerin internet adreslerinden ulaşılmıştır. Ayrıca, çeşitli uluslararası eğitim danışmanlı̆̆ hizmeti veren kuruluşların internet adreslerindeki arama motorlarından da yararlanılarak, girişimcilik bölümlerinin dünyadaki yaklaşık sayılanı tespit edilmeye çalışlısştır. Zaman kısıtı olması nedeniyle araştırma seçilmiş Dünya üniversiteleri ile sınırlı kalmış ve üniversitelerdeki girişimcilik bölümlerinin içeriklerine yer verilmemiştir.

\section{Bulgular}

YÖK'ün lisans atlasından 19.02.2018 tarihinde elde edilen verilere göre Türkiye'de Girişimcilik Lisans bölümü bulunan üniversiteler Tablo 1'de verilmiştir. Tablo 1 incelendiğinde, Türkiye'de 1'i devlet ve 4'ü vakıf olmak üzere toplam 5 üniversitede doğrudan girişimcilik alanında lisans düzeyinde eğitim verilmektedir. Girişimcilik alanında doğrudan lisans eğitimi veren üniversite Karabük Üniversitesi İşletme Fakültesi'dir. Vakıf üniversitelerinden TOBB Ekonomi ve Teknoloji Üniversitesi'nin doğrudan girişimcilik ile ilgili lisans bölümü eğitim faaliyetleri "Uluslararası Girişimcilik" adı altında gerçekleşmektedir ve bu haliyle diğer vakıf üniversitelerinden farklılık göstermektedir. TOBB Uluslararası Girişimcilik bölümün amac1, Türkiye'nin ticari ve siyasi ilişkilerini sürekli olarak arttırdığı Orta Doğu ülkelerinin kültürüne, tarihine, ekonomik ve ticari alt yapılarına hâkim girişimciler yetiştirmek şeklinde açıklanmıştır. Ders içeriğine bakıldığında ilk iki yll İngilizce işletme ve iktisat bölümlerinin derslerine benzer derslere rastlanmıştır. Son iki yılda ise ağırlıklı olarak Rusya ile ilgili derslere yer verilmiştir. Rus siyasi ve toplumsal tarihi, Rusya ve bölgesinde iş yapma pratikleri, Rusya ve bölge ekonomisi, Rusya hukuk sistemi gibi dersler Rusya'da girişimcilik yapmak isteyenler için ayrıallğa sahiptir (http://ugb.etu.edu.tr/tr/content/lisansprogrami-10, Erişim Tarihi: 23.02.2018). 
Tablo 1. Türkiye'de Girișimcilik Lisans Bölümü Bulunan Üniversiteler

\begin{tabular}{llll}
\hline Üniversite & Fakülte & Devlet / Vakıf & Lisans Bölüm Ad1 \\
\hline Karabük Üniversitesi. & İşletme Fakültesi & Devlet & Girişimcilik \\
İstanbul Kültür Üniversitesi & İ.İ.B.F. & Vakıf & Girişimcilik \\
İstanbul Şehir Üniversitesi & İşletme ve Yönetim Bilimleri & Vakıf & Girişimcilik \\
& Fakültesi & & \\
$\begin{array}{l}\text { Özyeğin Üniversitesi } \\
\text { TOBB Ekonomi ve Teknoloji }\end{array}$ & $\begin{array}{l}\text { İşletme Fakültesi } \\
\text { Ü.İ.B.F. }\end{array}$ & Vakıf & Girişimcilik (İngilizce) \\
\hline
\end{tabular}

Türkiye üniversitelerin girişimcilik lisansüstü bölümlerine ise Şubat 2018 dönemi itibariyle, üniversitelerin sosyal bilimler enstitülerinin resmi internet adreslerinden ulaşılarak, Tablo 2' deki veriler elde edilmiştir. Buna göre; Türkiye'de 2018 Şubat dönemi itibariyle 12'si devlet, 5’i vakıf, 1’i devlet - vakıf ortak olmak üzere toplam 19 üniversitede doğrudan girişimcilikle ilgili yüksek lisans bölümü bulunmaktadır. Bu 19 üniversiteden 9'u hem tezli hem tezsiz, 9'u tezsiz, 1'ise tezli girişimcilik yüksek lisans bölümü olarak eğitim vermektedir.

Tablo 2. Türkiye’de Girişimcilik Yükesek Lisans Bölümü Bulunan Üniversiteler

\begin{tabular}{|c|c|c|c|c|c|}
\hline & Üniversite & Enstitü & $\begin{array}{l}\text { Devlet / } \\
\text { Vakıf }\end{array}$ & Y.L. Bölüm Adı & $\begin{array}{l}\text { Tezli/ } \\
\text { Tezsiz }\end{array}$ \\
\hline 1 & İstanbul Teknik Üniversitesi & Sosyal Bilimler & Devlet & Girişimcilik ve Yenilikçilik Yönetimi & Tezsiz \\
\hline 2 & Y1ldız Teknik Üniversitesi & Sosyal Bilimler & Devlet & İnovasyon, Girişimcilik ve Yönetim & $\begin{array}{l}\text { Tezli / } \\
\text { Tezsiz }\end{array}$ \\
\hline 3 & Marmara Üniversitesi & Sosyal Bilimler & Devlet & $\begin{array}{l}\text { İnovasyon ve Girişimcilik Ekonomisi } \\
\text { (İktisat Anabilim Dalı'na Bağlı) }\end{array}$ & Tezsiz \\
\hline 4 & Dokuz Eylül Üniversitesi & Sosyal Bilimler & Devlet & Girişimcilik & $\begin{array}{l}\text { Tezli / } \\
\text { Tezsiz }\end{array}$ \\
\hline 5 & Trakya Üniversitesi & Sosyal Bilimler & Devlet & $\begin{array}{l}\text { Girişimcilik } \\
\text { (Girişimcilik Anabilim Dalı'na Bağlı) }\end{array}$ & $\begin{array}{l}\text { Tezli / } \\
\text { Tezsiz }\end{array}$ \\
\hline 6 & Düzce Üniversitesi & Sosyal Bilimler & Devlet & $\begin{array}{l}\text { Girişimcilik } \\
\text { (Girișimcilik Anabilim Dalı'na Bağlı) }\end{array}$ & $\begin{array}{l}\text { Tezli / } \\
\text { Tezsiz }\end{array}$ \\
\hline 7 & Karabük Üniversitesi & Sosyal Bilimler & Devlet & Girişimcilik & Tezsiz \\
\hline 8 & Gebze Teknik Üniversitesi & Sosyal Bilimler & Devlet & Girişimcilik ve Yenilik Yönetimi & Tezsiz \\
\hline 9 & $\begin{array}{l}\text { Bandırma Onyedi Eylül } \\
\text { Üniversitesi }\end{array}$ & Sosyal Bilimler & Devlet & Liderlik ve Küresel Girişimcilik & $\begin{array}{l}\text { Tezli / } \\
\text { Tezsiz }\end{array}$ \\
\hline 10 & Firat Üniversitesi & Sosyal Bilimler & Devlet & Girişimcilik ve Yenilik Yönetimi & $\begin{array}{l}\text { Tezli / } \\
\text { Tezsiz }\end{array}$ \\
\hline 11 & Bartın Üniversitesi & Sosyal Bilimler & Devlet & Girişimcilik & Tezsiz \\
\hline 12 & $\begin{array}{l}\text { Adana Bilim ve Teknoloji } \\
\text { Üniversitesi }\end{array}$ & Sosyal Bilimler & Devlet & Girişimcilik & $\begin{array}{l}\text { Tezli / } \\
\text { Tezsiz }\end{array}$ \\
\hline 13 & $\begin{array}{l}\text { İstanbul Üniversitesi / } \\
\text { Hasan Kalyoncu Üniversitesi } \\
\text { (Ortak) }\end{array}$ & Sosyal Bilimler & $\begin{array}{l}\text { Devlet / } \\
\text { Vakif }\end{array}$ & Liderlik ve Küresel Girişimcilik & Tezsiz \\
\hline 14 & Bahçeşehir Üniversitesi & Sosyal Bilimler & Vakıf & Girişimcilik ve İnovasyon Yönetimi & $\begin{array}{l}\text { Tezli / } \\
\text { Tezsiz }\end{array}$ \\
\hline 15 & Okan Üniversitesi & Sosyal Bilimler & Vakıf & Girişimcilik & $\begin{array}{l}\text { Tezli / } \\
\text { Tezsiz }\end{array}$ \\
\hline 16 & MEF Üniversitesi & Sosyal Bilimler & Vakıf & Girişimcilik & Tezsiz \\
\hline 17 & Özyeğin Üniversitesi & Sosyal Bilimler & Vakıf & Girişimcilik & Tezsiz \\
\hline 18 & İstanbul Bilgi Üniversitesi & Fen Bilimleri & Vakıf & $\begin{array}{l}\text { Teknolojide Girişimcilik ve } \\
\text { İnovasyon }\end{array}$ & Tezli \\
\hline
\end{tabular}

Girişimcilikle ilgili yüksek lisans bölümlerden sadece İstanbul Bilgi Üniversitesi’ndeki “Teknolojide Girișimcilik ve İnovasyon" bölümü fen bilimlerine bağlı, diğer üniversitelerdeki girișimcilik bölümleri ise sosyal bilimler enstitülerine bağlı bölümlerdir. Marmara Üniversitesi’ndeki "İnovasyon ve Girişimcilik Ekonomisi” yüksek lisans bölümü İktisat Anabilim Dalı'na bağlı, Trakya ve Düzce Üniversiteleri’ndeki girişimcilik yüksek lisans bölümleri ise doğrudan Girişimcilik Anabilim Dalı'na bağlıdır. Diğer üniversitelerin girişimcilik yüksek lisans bölümleri ise İşletme Anabilim Dalı'na bağlıdır. İstanbul Üniversitesi ile Hasan Kalyoncu Üniversitesi tezsiz “Liderlik ve Küresel Girişimcilik” bölümü ise DevletVakıf ortaklı̆̆ında yürütülen tek girişimcilik yüksek lisans bölümüdür. Ayrıca doğrudan girişimcilikle ilgili yüksek lisans bölümü bulunan 19 üniversiteden, 9'unda ilgili bölümün ismi yalnızca "Girişimcilik" iken diğer üniversitelerde, "Girişimcilik ve Yenilikçilik Yönetimi”, "İnovasyon, Girişimcilik ve Yönetim”, “İnovasyon ve Girişimcilik Ekonomisi”, "Liderlik ve Küresel Girişimcilik”, "Girişimcilik ve Yenilik 
Yönetimi”, “Teknolojide Girişimcilik ve İnovasyon” gibi farklı isimlerle de girişimcilik bölümlerinin açıldığı görülmektedir. Yapılan araştırmada, Türkiye'de üniversitelerin büyük bir bölümünde Girişimcilik Merkezleri bulunmakla birlikte, Türkiye'de doğrudan girişimcilik alanında eğitim veren bir "Doktora" bölümüne rastlanmamıştır.

Tablo 3. Dünya (Ilk. 10) Üniversitelerinin Girișimcilik Lisans ve Lisansüstü Bölümleri

\begin{tabular}{|c|c|c|c|c|c|c|}
\hline $\begin{array}{l}\text { S1ralama } \\
\text { (2018) }\end{array}$ & Üniversite & Lisans & $\begin{array}{l}\text { Yüksek } \\
\text { Lisans }\end{array}$ & Doktora & $\begin{array}{l}\text { Girişimcilik } \\
\text { Merkezi }\end{array}$ & Ülke \\
\hline$\frac{1}{1}$ & $\frac{\text { University of }}{\text { Oxford }}$ & & & & $\begin{array}{l}\text { Girişimcilik ve } \\
\text { Yaratıcilık Merkezi }\end{array}$ & $\overline{\text { İngiltere }}$ \\
\hline 2 & $\frac{\text { University of }}{\text { Cambridge }}$ & & Girişimcilik & & Girişimcilik Merkezi & İngiltere \\
\hline 3 & $\frac{\text { California }}{\frac{\text { Institute of }}{\text { Technology }}}$ & & & & Girişimcilik Kulübü & $\mathrm{ABD}$ \\
\hline 4 & $\frac{\text { Stanford }}{\text { University }}$ & Girişimcilik & & & $\begin{array}{l}\text { Girișimcilik } \\
\text { Çalıșmaları Merkezi }\end{array}$ & $\mathrm{ABD}$ \\
\hline 5 & $\begin{array}{l}\text { Massachusetts } \\
\text { Institute of } \\
\text { Technology }\end{array}$ & & & & Girişimcilik merkezi & $\mathrm{ABD}$ \\
\hline 6 & $\begin{array}{l}\text { Harvard } \\
\text { University }\end{array}$ & $\begin{array}{l}\text { Girişimcilik } \\
\text { Yönetimi }\end{array}$ & & & $\begin{array}{l}\text { Girişimcilik } \\
\text { Kulübü, Rock } \\
\text { Grrișimcilık Merkezi }\end{array}$ & $\mathrm{ABD}$ \\
\hline 7 & $\frac{\text { Princeton }}{\text { University }}$ & Girişimcilik & & & Girişimcilik Merkezi & $\mathrm{ABD}$ \\
\hline 8 & $\begin{array}{l}\text { Imperial College } \\
\text { London }\end{array}$ & $\begin{array}{l}\text { İnovasyon ve } \\
\text { Girişimcilik }\end{array}$ & $\begin{array}{l}\text { İnovasyon, } \\
\text { Girişimcilik } \\
\text { ve Yönetim }\end{array}$ & $\begin{array}{l}\text { İnovasyon ve } \\
\text { Girişimcilik }\end{array}$ & & İngiltere \\
\hline 9 & $\underline{\text { University of }}$ & Girişimcilik & Girişimcilik & & $\begin{array}{l}\text { Polsky Girişimcilik } \\
\text { ve İnovasyon } \\
\text { Merkezi }\end{array}$ & $\mathrm{ABD}$ \\
\hline \multirow{3}{*}{10} & $\frac{\text { ETH Zurich - }}{\frac{\text { Swiss Federal }}{\text { Institute of }}}$ & & & & $\begin{array}{l}\text { Yaratıcllık Ve } \\
\text { Girişimcilik } \\
\text { Laboratuvarı }\end{array}$ & İşviçre \\
\hline & $\begin{array}{l}\text { Technology } \\
\text { Zurich }\end{array}$ & & & & & \\
\hline & $\frac{\text { University of }}{\text { Pennsylvania }}$ & Girişimcilik & $\begin{array}{l}\text { Girişimcilik } \\
\text { Yönetimi }\end{array}$ & & $\begin{array}{l}\text { Penn Wharton } \\
\text { Girișimcilik } \\
\text { Merkezi, Sol C. } \\
\text { Snider Girișimcilik } \\
\text { Araştırmalar1 } \\
\text { Merkezi }\end{array}$ & $\mathrm{ABD}$ \\
\hline
\end{tabular}

Kaynak: https://www.timeshighereducation.com/world-university-rankings/2018/worldranking\#survey -answer adresindeki sıralamaya göre, üniversitelerinin web adreslerinden yararlanılarak düzenlenmiştir.

The Times Higher Education tarafindan hazırlanan Dünyanın en iyi üniversiteleri listesindeki ilk on üniversitenin girişimcilik lisans ve lisansüstü bölümleri incelenerek Tablo 3 düzenlenmiştir. İlgili üniversiteler ABD başta olmak üzere, İngiltere ve İsviçre gibi ülkelerde eğitim vermektedir. Buna göre, dünyanın en iyi ilk on üniversitesinden 6'sında girişimcilik lisans bölümü, 4'ünde girişimcilik yüksek lisans bölümü, 1'inde ise doğrudan girişimcilikle ilgili doktora bölümüne rastlanmıştır. Dünyanın en iyi ilk 10 üniversiteleri sıralamasinda 8. Sirada bulunan İngiltere'deki "Imperial College London" bünyesinde, doğrudan girişimcilik alanında eğitim veren hem lisans, yüksek lisans, hemde doktora bölümü bulunmaktadır. Bu 10 üniversiteden 9'unda ise Girişimcilik alanında öğrencilere eğitimler ve destekler veren "Girişimcilik Merkezleri” bulunmaktadır. Bu durum dünyanın en iyi üniversitelerinin girişimcilik eğitimine verdiği önemi açıcça göstermektedir. Girişimcilikle ilgili lisans, yüksek lisans ve doktora programlarında, karşılaşılan bölüm ismi genellikle ülkemizde de olduğu gibi "Girişimcilik" dir. Ayrıca, "Girişimcilik Yönetimi”, "İnovasyon ve Girişimcilik", "İnovasyon, Girişimcilik ve Yönetim” gibi bölüm isimleri ile de karşılaşılmıştır.

Dünyanın işletme alanında eğitim veren en önemli üniversitelerinden biri olan Harvard İşletme Okulu, kendilerini benzersiz k1lan önemli faktörlerden biri olarak "Girișimcilik ve İnovasyon" kavramını ön plana çıkarmıştır. Öğrencilerine potansiyel girişimlerin keşfedilmesi, girişimcilerle bağlantı kurulması ve üniversitenin e-lab. vb. girişimcilikle ilgili benzersiz kaynaklarından ve hizmetlerinden faydalanmaları 
konularında tavsiyelerde bulunmakta ve her türlü desteği sağlamaktadır (https://www.hbs.edu/mba/thehbs-difference/Pages/default. aspx, Erişim Tarihi: 12.03.2018).

Aynıca, çeşitli uluslararası eğitim danışmanlığı hizmeti veren kuruluşlar ile lisans, yüksek lisans ve doktora alanında eğitim veren üniversiteleri listeleyen uluslararası eğitim kuruluşlarının internet arama motorları üzerinden yapılan filtrelemeler sonucunda, Dünya’da doğrudan girişimcilik lisans eğitimi veren yaklaşık 550, yüksek lisans eğitimi veren yaklaşık 300 üniversite, Dünya'da doğrudan girişimcilik ile ilgili alanlarda doktora eğitimi veren ise yaklaşık 30 adet üniversite tespit edilmiştir. Bu üniversitelerden girişimcilik yüksek lisans eğitimi veren üniversitelerin, yaklaşık yüzde 50'si Avrupa'da, yaklaşı1k üçte biri ise ABD'de bulunan üniversitelerdir. Doktora seviyesinde girişimcilik eğitimi veren üniversitelerin yaklaşık üçte ikisi $\mathrm{ABD}$ ve İngiltere'de bulunmaktadır (https://www.hotcourses-turkey.com/ ve https://tr.phdstudies.com adreslerinden yapilan filtrelemeler sonucunda elde edilen yaklaşık ortalama verilerdir).

Diğer yandan, Türkiye'deki girişimcilik bölüm isimlerinden farklı olarak Dünya'da doğrudan girişimcilikle ilgili yüksek lisans bölümleri "İletişim ve Girişimcilik", "Elektronik Mühendisliği ve Girişimcilik", "Sürdürülebilir Enerji ve Girişimcilik", "Yaratıc1 ve Kültürel Girişimcilik", "Sosyal Girişimcilik” gibi isimlerde de açılmakta; Dünya’da doğrudan girişimcilikle ilgili doktora bölümleri ise "Teknoloji Girişimciliğinde İșletme Yönetimi”, "İșletme ve Girișimcilik", "Strateji ve Girișimcilik", "Uluslararası Eğitim ve Girişimcilik", "Girişimcilik ve Endüstriyel Ekonomi”, "Teknolojik Değişim ve Girişimcilik", "Girişimcilik Eğitimi ve İşletme Çalışmaları" gibi bölüm isimleri altında da eğitim vermektedir.

Aşağıda farklı dünya ülkelerinden, girişimcilik doktora bölümlerine örneklere de Tablo’4 de yer verilmiştir.

Tablo 4. Dünya'da Girişimcilik. Doktora Bölümü Bulunan Bą̧ Üniversite Örnekleri

\begin{tabular}{lll}
\hline Üniversite & Doktora Program Adı & Ülke \\
\hline Osijek Üniv. Ekonomi Fakültesi & Girişimcilik ve Yenilikçilik & Hirvatistan \\
Horizons Üniv. & Uluslararası Girişimcilik & Fransa \\
Telfer Yönetim Okulu & Girişimcilik & Kanada \\
ABMS Open Üniv. & Girişimcilik & Isviçre \\
Kiev Ulusal Taras Shevchenko Üniv. & Girişimcilik, Ticaret ve Değişim Faaliyetleri & Ukrayna \\
California Kitalararası Üniv. & Girişimcilik ve İşletme Yönetimi & ABD \\
\hline
\end{tabular}

Kaynak: https://tr.phdstudies.com/Doktora/Giri\%C5\%9Fimcilik/ adresindeki verilerden yararlanılarak ve ilgili üniversitelerinin web sayfaları üzerinden araştırma yapılarak düzenlenmiştir.

Uluslararası eğitim danışmalık firmalarının arama motorlarından yapılan filtrelemeler sonucunda ve YÖK Lisans Atlas verileri ile üniversitelerin Sosyal Bilimler Enstitüleri’nin web sayfalarından yararlanılarak Tablo 5 oluşturulmuştur. Tablo 5 incelendiğinde Türkiye'de Girişimcilik lisans bölümlerinin sayısının yüksek lisansa oranla oldukça düşük olduğu dikkat çekmektedir. Türkiye'de Girişimcilik bölümleri henüz başta işletme bölümü olmak üzere iktisadi ve idari bölümlerde verilen bir ders olmanın çıkmamıştır.

Girişimcilik bölümlerinin sayılarındaki artışta ve buna bağlı olarak başarllı girişimcilik faaliyetlerinde bulunacak eğitimli girişimcilerin sayılarındaki artışta, üniversitelerin atacakları adımlar büyük önem arz etmektedir.

Tablo 5. Türkiye ve Dünya Üniversitelerinde (Yaklaşı) Girişimcilik Lisans, Yüksek Lisans ve Doktora Bölüm Saylar

\begin{tabular}{llll}
\hline & Lisans & Yüksek Lisans & Doktora \\
\hline Dünya Üniversiteleri & $550^{*}$ & $300^{*}$ & $30^{*}$ \\
Türkiye Üniversiteleri & $5^{* *}$ & $19^{* *}$ & - \\
\hline *Uluslararası eğitim danı̧malık firmalarının arama motorlarından yapılan filtrelemeler sonucu elde edilmiştir. \\
** YÖK Lisans Atlas verileri ve üniversitelerin Sosyal Bilimler Enstitüleri’nin web sayfalarından yararlanılmıştır.
\end{tabular}

Yapılan araştırmadan elde edilen bazı sonuçlar şöyle özetlenebilir:

- Dünya Üniversiteleri ile Türkiye Üniversiteleri kıyaslandığında, Türkiye'de henüz doğrudan girişimcilik alanında lisans eğitimi veren üniversitelerin sayısı (5) çok azdır. Doğrudan girişimcilik lisans bölümü bulunan tek devlet üniversitesi Karabük Üniversitesi'dir. Bir vakıf üniversitesi olan 
TOBB Ekonomi ve Teknoloji Üniversitesi ise "Uluslararası Girişimcilik" bölümü adı altında eğitim veren tek üniversitedir.

- Türkiye'deki toplam üniversite sayısı düşünüldüğünde, doğrudan girişimcilik alanında yüksek lisans eğitimi veren üniversite sayısı da (19) istenilen düzeyde değildir. Üstelik bu bölümlerin büyük bir kısmı tezsizdir. Bu üniversitelerden Düzce Üniversitesi’nin ve Trakya Üniversitesi’nin girişimcilik yüksek lisans eğitimleri "Girişimcilik Anabilim Dalı"na bağlı olarak gerçekleşmektedir ve bu şekliyle Türkiye'deki diğer üniversitelerin girişimcilik yüksek lisans bölümlerinden farklllık göstermektedir.

- Dünya'da doğrudan girişimcilik lisans eğitimi veren yaklaşık 550, yüksek lisans eğitimi veren yaklaşık 300 üniversite, Dünya'da doğrudan girişimcilik ile ilgili alanlarda doktora eğitimi veren ise yaklaşı 30 adet üniversite tespit edilmiştir. Bu üniversitelerden girişimcilik yüksek lisans eğitimi veren üniversitelerin, yaklaşık yüzde 50'si Avrupa'da, yaklaşık üçte biri ise ABD'de bulunan üniversitelerdir. Doktora seviyesinde girişimcilik eğitimi veren üniversitelerin yaklaşık üçte ikisi ABD ve İngiltere'de bulunmaktadır.

- Türkiye'deki üniversitelerdeki girişimcilik yüksek lisans bölüm isimleri ağırlıklı olarak "girişimcilik" başlı̆̆ altında toplanmış ve birkaç üniversite hariç sosyal bilimler enstitülerindeki belirli anabilim dallarıyla sınırlı kalmıştır. Türkiye'deki girişimcilik bölüm isimlerinden farklı olarak Dünya'da doğrudan girişimcilikle ilgili yüksek lisans bölümlerinin "İletişìm ve Girişsimcilik", "Elektronik Mühendisliği ve Girişimcilik", "Sürdürülebilir Enerji ve Girişimcilik", "Yaratıcı ve Kültürel Girişimcilik", "Sosyal Girişimcilik” gibi isimlerde eğitim verdikleri görülmektedir. Bu konularda Dünya Üniversitelerdeki farklı disiplinleri de kapsayan girişimcilik yüksek lisans bölümlerinin incelenmesi, üniversitelerimizdeki girişimcilik bölümlerinin çağın gereklerini yakalamaları açısından yararlı olacaktır.

- Türkiye'de doğrudan girişimcilik alanında doktora eğitimi veren bir üniversite tespit edilememiştir. Bu konuda çalışmamızda da yer alan bazı Dünya Üniversitelerinin doğrudan girişimcilik doktora bölüm örneklerinin incelenmesi ve ülkemizdeki üniversiteler tarafindan gerekli adımların atılması "girişimci üniversite" kavramının altının doldurulmasına katkı sağlayacaktır. Dünyanın en iyi ilk 10 üniversiteleri sıralamasında bulunan İngiltere'deki "Imperial College London" bünyesinde doğrudan girişimcilik alanında eğitim veren hem lisans, yüksek lisans, hem de doktora bölümü bulunmaktadır.

- Üniversite girişimcilik merkezleri, girişimcilik kulübü - topluluğu gibi oluşumlara Dünyanın en iyi üniversitelerinin neredeyse tamamı büyük önem vermektedir ve bu merkezler aracilığtyla öğrencilerine girişimcilik eğitimleri sunmaktadır. Türkiye'de ise birçok üniversitede doğrudan girişimcilik bölümü olmasa bile girişimcilik merkezlerinin var olduğu ve bu merkezler aracilgğ ile geleceğin başarılı girişimcilerini yetiştirmek amacıyla eğitimler verildiği görülmektedir.

- Dünyanın işletme alanında eğitim veren en önemli üniversitelerinden biri olan Harvard İşletme Okulu, kendilerini benzersiz kılan 6 farklılaştırıcıdan biri olarak "Girişimcilik ve İnovasyon" kavramını ön plana çıkarmıştır. Öğrencilerine potansiyel girişimlerin keşfedilmesi, girişimcilerle bağlantı kurulması ve üniversitenin e-lab. vb. girişimcilikle ilgili benzersiz kaynaklarından ve hizmetlerinden faydalanmaları konularında tavsiyelerde bulunmakta ve her türlü desteği sağlamaktadır. Benzer modellerin, Türkiye'deki üniversiteler tarafından benimsenmesinin de girişimcilik eğitiminin yaygınlaşmasına ve daha nitelikli hale gelmesine katkı sağlayarak, üniversitelerin girişimci ve yenilikçi üniversite endekslerine ve böylelikle ülke ekonomisine ve topluma olumlu yansımalarının olacağı söylenebilir.

\section{Sonuç ve Öneriler}

Girişimcilik eğitiminin oldukça önemli olması ve öneminin de gittikçe artmasına karşın, bu alana ilişkin eğitim veren üniversitelerdeki girişimcilik bölümlerinin sayıları çok azdır. Üniversitelerdeki girişimcilik bölümleri, gençlere önlerine çıkacak firsatları fark etmelerine, sağlıklı ve doğru kararlar alarak bunları iş fikrine dönüştürmelerine olanak tanımaktadır. Aynı zamanda bu fikirlerin üretime dönüştürülerek kar elde edilebilir ürün ve hizmetler ortaya çıkmasına yardımcı olmakta ve gençlere istihdam yaratan, yeniliğe açık, modern, vizyon sahibi işletmeler kurmaları konusunda eğitim vermeyi hedeflemektedir.

Üniversitelerde öğrencilerin girişimcilik ruhlarını geliştirmek ve mezun olduklarında kendi işletmelerini açarak; ekonomi, istihdam gibi konulara katkı sağlamalarını sağlamak amaçlarıyla birçok bölüm ve programda girişimcilik dersleri yaygınlaşmakta ve girişimcilik merkezleri kurularak, bu 
merkezlerde de öğrencilere girişimcilikle ilgili uygulamalı proje eğitimleri verilmektedir. Girișimcilik eğitiminde yaşanan bu olumlu gelişmelere, son zamanlarda Dünya ve Türkiye üniversitelerinde doğrudan açılan, Girişimcilik Anabilim Dallarının ve girişimcilik lisans ve lisansüstü programlarının da önemli katkılar sağlayacağı düşünülmektedir.

Dünya genelinde girişimciliğin gelişmesi ve bu alanda istenilen sonuçların daha sağlıklı elde edilebilmesi için gerekli olan girişimcilik eğitiminin artan önemine bağlı olarak, Türkiye üniversitelerinde de açılan girişimcilik bölümlerinin sayısının arttığı görülmektedir.

Dünyada girişimcilik eğitimi birçok üniversitede açılan girişimcilik bölümlerinde ve merkezlerinde yürütülmektedir. Türkiye'de doğrudan girişimcilik lisans ve lisansüstü bölümü adı altında eğitim veren üniversite sayısının sınırlı olduğu görülmektedir. Uluslararası rekabet koşullarına uyum sağlamada, işletmeler açısından global normları yakalamada ve yeni başarılı girişimlerin ortaya çıkarılarak ülke ekonomisinin canlanmasında ülkemizdeki üniversitelerin açmış oldukları doğrudan girişimcilik bölümlerinin de dünya üniversitelerine paralel, global niteliklere sahip olması önem arz etmektedir.

Son y1llarda Türkiye'deki üniversiteler ile özellikle KOSGEB, ISSSUR gibi kurumlar arasında yürütülen girişimcilik sertifikası vermeye yönelik birçok program da bulunmaktadır. İlerleyen çalışmalarda bu programlar ve sonuçlarıyla ilgili değerlendirmeler de yapılabilir.

Ülkemizde üniversitelerde de girişimcilik eğitiminin ve bölümlerinin istenilen niteliğe ve sayıya ulaşması ile girişimcilikle ilgili daha nitelikli bilimsel çalışmaların ortaya çıkması olanağı doğacaktır. Bunun sonucunda da Türkiye'de girişimcilik konusunda her geçen gün daha bilinçli nesillerin yetişeceği ve bu gelişmelerin başta istihdam ve yenilikçilik olmak üzere ülke ekonomisine olumlu katkılarının olacağ1 düşünülmektedir.

Sonuç olarak, Ülkemizdeki üniversitelerde girişimcilik eğitiminin, "yalnızca bazı programların ders planlarında yer alan bir ders" olarak sınırlı kalmaması; doğrudan girișimcilik alanında eğitim veren lisans ve lisansüstü bölümlerin sayısının, niteliğinin artması ve dünya üniversitelerinde örneklerinin görüldüğü gibi girişimcilik bölümlerinin farklı disiplinlere de yayılmasının gerekli olduğu düşünülmektedir. Böylelikle, Türkiye'de girişimcilik alanında ulaşılmak istenilen global normlarla daha hızlı bir şekilde yakalanabilecektir; ekonomik gelişme ve toplumsal kalkınmanın sağlanması kolaylaşacaktır.

\section{Etik Beyan}

"Dünya ve Türkiye Üniversitelerinde Girişimcilik Bölümlerinin Artan Önemi: Lisans ve Lisansüstü Eğitim Düzeyinde Bir Araştırma" başlıklı çalısmanın yazım sürecinde bilimsel, etik ve alıntı kurallarına uyulmuş; toplanan veriler üzerinde herhangi bir tahrifat yapılmamış ve bu çalşsma herhangi başka bir akademik yayın ortamına değerlendirme için gönderilmemiştir.

\section{Kaynakça}

Akdemir, A. (2009). İsletmeciligigin temel bilgileri. Bursa: Ekin Yayınevi.

Akpınar, S. (2009). Girisimciligin temel bilgileri. Kocaeli: Umuttepe Kitabevi.

Balaban, Ö. ve Özdemir, Y. (2008). Girişimcilik eğitiminin girişimcilik eğilimi üzerindeki etkisi: Sakarya Üniversitesi örneği. Girişimcilik ve Kalkenma Dergisi, 3(2), 134-148.

Berglund, H., \& Wennberg, K. (2006). Creativity among entrepreneurship students: comparing engineering and business education. International Journal of Continuing Engineering Education and Liff-long Learning, 16(5), 366-379.

Bozkurt Çetinkaya, Özlem. (2011). Dünyada ve Türkiye’de girrșimcilike eğitimi: bașarhl girișimciler ve ögretim ïyelerinden öneriler. Ankara: Detay Yayınyıcllik.

Çetindamar, D. (2002). Türkizye' de girişimcilik. Ankara: Tüsiad Yayınları.

Galloway, L., \& Brown, W. (2002). Entrepreneurship education at university: a driver in the creation of high growth firms? Education \& Training, 44, 8-9.

Güler, B. K. (2009). Dünyada öncü üniversitelerin işletme fakültelerinin sosyal girişimcilik ile ilgili eğitsel ve bilimsel faaliyetleri. VI. Uluslararası STK'lar Kongresi, 23-25 Ekim 2009 Çanakkale.

Gürol, Y. ve Bal, Y. (2009). Türkiye'de girişimciliğin evrimi ve gelişimi için girişimcilik eğitiminin önemi. Retrieved from www.ikt.yildiz.edu.tr/RePEc/yil/makaleler/gurol 0019.pdf.

Harvard Business School (2018). Retrieved from https://www.hbs.edu/mba/the-hbsdifference/ Pages/default.aspx. Hotcourses International (2018). Retrieved from https://www.hotcourses-turkey.com/.

İşcan, Ö. F. ve Kaygın, E. (2011). Potansiyel girişimciler olarak üniversite öğrencilerinin girişimcilik eğilimlerini belirmeye yönelik bir araştırma. Organizasyon ve Yönetim Bilimleri Dergisi, 3(2), 275-286.

Keystone Academic Solutions (2018). Retrieved from https://tr.phdstudies.com. 
Küçük, O. (2009). Türk eğitim sisteminde girişimcilik ve girişimcilik eğitiminde Avrupa Birliği (AB) hibe projelerinden yararlanma düzeyi: Bir uygulama, 2. Uluslararası Girișimcilik Kongresi, Kırgızistan.

Liñán, F., Moriano, J. A., \& Zarnowska A. (2008). Teaching psychology of entrepreneurship perspective from six European countries. Madrid: Universidad Nacional de Educación a Distancia.

Özdem, G. ve Sarı, E. (2008). Yükseköğretimde yeni bakış açılarıyla birlikte yeni kurulan üniversitelerden beklenen işlevler (Giresun Üniversitesi örneği). Üniversite ve Toplum Dergisi, 8(1), 1-15.

Paço, A., \& Raposo, M. (2011). Entrepreneurship education: Relationship between educationand entrepreneurial activity. Psicothema 2011. 23(3), 453-457.

Rasmussen, E. A., \& Sorheim, R. (2006). Action-based entrepreneurship education. Technovation, 26, 185-194.

Segal, G., Borgia, D. \& Schoenfeld, J. (2005). The Motivation to Become an Entrepreneur, International Journal of Entrepreneurial Behaviour \& Research, 11(1), 42-57.

Şengel, S. (2008). Yükseköğretimde girişimcilik eğitiminin ınovatif iş fikirlerine ulaşmadaki etkisi uzerine bir araştırma, Uluslararası Girişimcilik Kongresi, Kırgızistan.

Sexton, D. L., \& Upton, N. B. (1987). Evaluation of an innovative approach to teaching entrepreneurship. Journal of Small Business Management, 25(1), 35-43.

Solomon, G. T., Duffy, S., \& Tarabishy, A. (2002). The state of entrepreneurship education in the United States: A nationwide survey and analysis. International Journal of Entrepreneurship Education, 1(1), 65-86.

Soylu, A. ve Kepenek, Y. (2008). Meslek yüksekokulu öğrencilerinin girişimcilik düzeyleri ve aldıkları eğitimin girişimciliğe olan katkılarının belirlenmesi: PAU Honaz Meslek Yüksekokulu örneği. Uluslararası Girişimcilik Kongresi, Kirgizistan.

Tağraf, H. ve Halis, M. (2008). Üniversitelerdeki girişimcilik eğitiminin “Girişimsel Öz Yetkinlik” alg1sı üzerindeki etkisi: Bir araştırma. Girişimcilik ve Kalkınma Dergisi, 3(2), 91-111.

TEB Özel BNP Parıas Ortaklığ1, Melek Yatırım Platformu (2018). Retrieved from https://www.melekyatirimplatformu.com/tr.

Tekin, M. (2004). Girisimcilik ve kü̈ü̈ isletme yöneticiliği. Ankara: Günay Ofset.

The World University Rankings (2018). Retrieved from https://www.timeshighereducation.com/world-universityrankings/2018/world-ranking\#survey-answer.

Yelkikalan, N., Akatay, A., Yıldırım, H. M., Karadeniz, Y., Köse, C., Koncagül, Ö. ve Özer, E. (2010). Dünya ve Türkiye üniversitelerinde girişimcilik eğitimi: Karşılaştırmalı bir analiz. KMÜ Sosyal ve Ekonomik Araştırma Dergisi, 12(19), 51-59.

Yıldırım, A. ve Şimşek, H. (2008). Sosyal bilimlerde nitel araştirma yöntemleri. Ankara: Seçkin Yayıncılık.

Yılmaz, C., Özdil, T., Tezsürücü D. ve Karadeniz, Y. (2010). Farklı egitim düzeyindeki üniversite ögrencilerinin girişimcilik konusunda görüş farklılığının araştırılması. Uluslararası II. Trakya Bölgesi Kalkemma-Girisimcilik Sempодуити (ss.157-173). Kurklareli, Türkiye.

\section{EXTENDED ABSTRACT}

Entrepreneurship is of great importance for the improvement of the problems in the economies of the country and for the development of the economy and social development. Recently, entrepreneurship issues have been emphasized, especially in developing countries.

In the development of entrepreneurship, it is important for universities both to reach to an entrepreneurial structure and to mainstream entrepreneurship departments and education through which people improve their entrepreneurial qualities.

The aim of this study was to the world and licenses directly related to entrepreneurship, which opened in Turkey college and the status of graduate programs put forth in a comparative manner and to clarify the contribution in terms of growth and economies of successful entrepreneurs of these programs.

In this study, firstly the concept of entrepreneurship and the importance of entrepreneurship are emphasized. Afterwards, literature review covering entrepreneurship education and some studies in this field is given.

The universe of the research, entrepreneurship undergraduate and graduate chapters in Turkey by The Times Higher Education published by the "best universities in the world 2018" constitutes the top ten universities in the world rankings.

In the study, the current situation in Turkey in entrepreneurship education is evaluated by identifying and comparing the direct entrepreneurship undergraduate and graduate programs of the universities in Turkey and of the top ten universities included in the List of World's Best Universities that has been prepared by The Times Higher Education. In this survey, a "content analysis" is performed through investigating the conditions of the universities in Turkey by analyzing the atlas data of The Council of Higher Education (YÖK) and the official websites of the institute of social sciences of the universities, 
and by accessing the undergraduate, graduate and PHD programs of the World's Top Ten Universities through their websites.

Entrepreneurship education is very important and its importance is increasing, but the number of entrepreneurship departments in universities providing education in this field is very small. Entrepreneurship departments in universities enable young people to realize the opportunities they will face and to make healthy and right decisions and turn them into business ideas. At the same time, these ideas help to produce profitable products and services by transforming them into production and aiming to train young people to establish modern, visionary enterprises that create employment and are open to innovation.

To develop the entrepreneurial spirit of students in universities and by opening their own businesses when they graduate; Entrepreneurship courses are becoming widespread in many departments and programs with the aim of contributing to the subjects such as economy and employment, and entrepreneurship centers are established and practical project trainings are given to the students in these centers. These positive developments in entrepreneurship education, recently opened directly in the university world and in Turkey, the Department of Entrepreneurship and entrepreneurship for undergraduate and graduate programs are also expected to make an important contribution.

World entrepreneurship development in general and the desired results in this field in order to achieve a more healthy due to the growing importance of entrepreneurship education is necessary, Turkey has increased the number of the opened section of entrepreneurship in universities.

Approximately 550 universities providing direct entrepreneurship undergraduate education, approximately 300 universities providing graduate education, and 30 universities providing doctorate education in the fields of direct entrepreneurship have been identified in the world. Among these universities, approximately 50 percent of the universities that provide graduate education in entrepreneurship are in Europe and about one third are in the USA. Approximately two-thirds of universities that offer entrepreneurship education at the doctoral level are located in the United States and the United Kingdom. Entrepreneurship graduate departments at universities in Turkey mainly names of "entrepreneurship" and collected under the title remained limited to specific departments except the few universities in the social sciences. Directly in the field of entrepreneurship in Turkey it could not be determined that a university doctorate.

In our country, it will be possible to have more qualified scientific studies related to entrepreneurship by reaching the desired quality and number of entrepreneurship education and departments in universities. As a result, entrepreneurship in Turkey will grow up every day and be more conscious generation of a positive contribution to the national economy, including employment and innovation is considered first of these developments.

In this context, it is considered that the entrepreneurship education in universities should not be limited to be "a course that take part in only some programs' instructional plan"; instead, the number and qualities of the programs that provide education in the field of entrepreneurship should be increased and spread to different disciplines. 